\title{
Dominant-negative and targeted null mutations in the endothelial receptor tyrosine kinase, tek, reveal a critical role in vasculogenesis of the embryo
}

\author{
Daniel J. Dumont,, ${ }^{1,5,6}$ Gérard Gradwohl, ${ }^{2}$ Guo-Hua Fong, ${ }^{1}$ Mira C. Puri, ${ }^{1,3}$ Marina Gertsenstein, ${ }^{1}$ \\ Anna Auerbach, ${ }^{1}$ and Martin L. Breitman ${ }^{1,3,4}$ \\ 'Division of Molecular and Developmental Biology, Samuel Lunenfeld Research Institute, Mount Sinai Hospital, Toronto, \\ Ontario, Canada ${ }^{2}$ Laboratoire de Génétique Moléculaire des Eucaryotes, Centre National de la Recherche Scientifique \\ (CNRS), Unité 184 de Biologie Moléculaire et de Génétique, Institut National de la Santé et de la Recherche Médicale \\ (INSERM), Institut de Chimie Biologique, Faculté de Médecine, Strasbourg, France; ${ }^{3}$ Department of Molecular and Medical \\ Genetics, University Toronto,Toronto, Ontario, Canada
}

The receptor tyrosine kinases (RTKs) expressed on the surface of endothelial cells are likely to play key roles in initiating the program of endothelial cell growth during development and subsequent vascularization during wound healing and tumorigenesis. Expression of the Tek RTK during mouse development is restricted primarily to endothelial cells and their progenitors, the angioblasts, suggesting that Tek is a key participant in vasculogenesis. To investigate the role that Tek plays within the endothelial cell lineage, we have disrupted the Tek signaling pathway using two different genetic approaches. First, we constructed transgenic mice expressing a dominant-negative form of the Tek receptor. Second, we created a null allele of the tek gene by homologous recombination in embryonic stem (ES) cells. Transgenic mice expressing dominant-negative alleles of Tek or homozygous for a null allele of the tek locus both died in utero with similar defects in the integrity of their endothelium. By crossing transgenic mice that express the lac $Z$ reporter gene under the transcriptional control of the endothelial cell-specific tek promoter, we found that the extraembryonic and embryonic vasculature was patterned correctly. However, homozygous tek embryos had $\sim 30 \%$ and $75 \%$ fewer endothelial cells at day 8.5 and 9.0, respectively. Homozygous null embryos also displayed abnormalities in heart development, consistent with the conclusion that Tek is necessary for endocardial/myocardial interactions during development. On the basis of the analysis of mice carrying either dominant-negative or null mutations of the tek gene, these observations demonstrate that the Tek signaling pathway plays a critical role in the differentiation, proliferation, and survival of endothelial cells in the mouse embryo.

[Key Words: Receptor tyrosine kinase; endothelial cell growth; Tek; vasculogenesis; transgenic mice; homozygous embryos]

Received June 1, 1994; revised version accepted July 7, 1994.

The receptor tyrosine kinase (RTK) family of cell-surface proteins is known to play key roles in cell-cell communication in multicellular metazoan organisms (Pawson and Bernstein 1991|. Genetic and biochemical studies on this large family of proteins have shown that different RTKs are responsible for transducing important developmental, proliferative, cell survival, and migratory signals from the outside to the inside of the cell (Hunter and Lindberg 1994). The development and proper functioning of cell systems as diverse as the compound eye in the fly, the vulva in the nematode, and hematopoiesis in the

\footnotetext{
${ }^{4}$ This manuscript is dedicated to the memory of Dr. Martin L. Breitman, who died on February 13, 1994.

${ }^{5}$ Corresponding author.

${ }^{6}$ Present address: AMGEN Institute, Toronto Ontario M5G 2C1, Canada.
}

mouse all depend on intact signaling pathways that are controlled by different members of the RTK family (Reith and Bernstein 1991; Pawson 1993).

Five RTKs have been identified whose expression is restricted primarily to cells of the endothelial lineage. On the basis of similarities in their primary amino acid sequences, they have been placed into two distinct subfamilies of RTKs (Dumont et al. 1993; Hunter and Lindberg 1994). The members of one subfamily, including Flt-4 (Pajusola et al. 1992) and the Vascular endothelial growth factor (VEGF) receptors Flt-1 (Matsushime et al. 1987; Shibuya et al. 1990) and Flk-1/KDR (Terman et al. 1991; Millauer et al. 1993), are characterized by extracellular domains consisting of seven immunoglobulinlike loops and an intracellular split kinase domain. The second subfamily contains the two receptors Tek and 
Tie (Wilks 1989; Dumont et al. 1992, 1993; Partanen et al. 1992; Iwama et al. 1993; Maisonpierre et al. 1993; Sato et al. 1993; Ziegler et al. 1993), both of whom have complex extracellular domains consisting of two immunoglobulin-like loops separated by three EGF-like repeats that are followed by three fibronectin type III-like repeats. The intracellular portions of Tek and Tie also contain a split kinase domain.

The differing spatial and temporal patterns of expression of these RTKs during development suggest that they play different roles within the endothelial cell lineage. Very early in development [embryonic day 7.0 (E7.0)], flk-1 is expressed in both the extraembryonic and embryonic mesoderm in regions thought to give rise eventually to the embryonic vasculature (Millauer et al. 1993; Yamaguchi et al. 1993; D. Dumont, G.-H. Fong, M.C. Puri, G. Gradwohl, K. Alitalo, and M. Breitman, in prep.). tek can then be detected in regions that overlap with the flk-1-positive extraembryonic mesoderm at E7.5, and finally, tie is detected at E8.0 in the flk-1- and tek-expressing extraembryonic mesoderm (D. Dumont, G.-H. Fong, M.C. Puri, G. Gradwohl, K. Alitalo, and M. Breitman, in prep.). The early onset of $f l k-1$ expression (E7.0) suggests a role for this receptor early in the determination of the endothelial cell lineage (Yamaguchi et al. 1993), whereas the later, sequential onset of both tek and tie expression suggests that these RTKs may play distinct roles during subsequent vascularization of the embryo.

Little is known about the expression of flt-1 and flt-4 in the mouse. One report has stated that flt-1 is expressed in the endothelium of E9.5 embryos (Peters et al. 1993|, but as the onset of expression was not determined in these studies, it is not known whether flt-1 may also play an earlier role during vascularization. Although the localization and timing of flt-4 expression in the mouse has not been reported, studies on human fetal tissue have reported FLT-4 expression in the epithelium lining the bronchioles of the lung and in the vascular endothelium (Pajusola et al. 1992; Kaipainen et al. 1994). Quek1 , the quail homolog of $f l k-1$, is expressed, as in the mouse, in the mesoderm from the onset of gastrulation, whereas the expression of Quek-2, a distinct RTK related most closely to $f l t-4$, is found later in endothelial cells that stain with the endothelial cell-specific antibody QH1 (Eichmann et al. 1993).

Our studies have focused on the biological function of the murine RTK, Tek, first identified from a cDNA library prepared from E12.5 embryonic heart (Dumont et al. 1992, 1993). The tek gene encodes a $140-\mathrm{kD}$ protein with intrinsic tyrosine kinase activity (Dumont et al. 1993; Ziegler et al. 1993) that is expressed in the endothelium of the embryo, in embryonic stem (ES) cells induced to differentiate in vitro (Yamaguchi et al. 1993), in endothelial cell lines (Dumont et al. 1993), and in early $\mathrm{Sca}^{+}, \mathrm{c}-\mathrm{kit}^{+}, \mathrm{lin}^{-}$hematopoietic stem cell populations (Iwama et al. 1993). To understand the role of the Tek RTK in mouse development, we have taken two genetic approaches to disrupt the Tek signaling pathway in vivo. The first strategy was to interfere with the Tek signaling pathway by expressing a dominant-negative form of Tek in transgenic mice. Previous studies have shown that structural mutations that abolish or diminish the intrinsic tyrosine kinase activity of other RTKs act in a dominant-negative manner in both cells and in the intact organism. For example, naturally occurring mutations in the Kit RTK in the dominant white-spotting $(W)$ mouse mutant act in a dominant-negative manner to inhibit melanogenesis, hematopoiesis, and gametogenesis (Reith et al. 1990). Similarly, expression of other RTKs with mutations that reduce their intrinsic tyrosine activity act in a dominant-negative fashion to inhibit the signaling through the corresponding wild-type receptor in mammalian cell lines (Reith et al. 1993), in frog embryos (Amaya et al. 1991), in transgenic mice (Ray et al. 1991), and in tumor angiogenesis (Millauer et al. 1994). Second, we created a tek null allele by homologous recombination in ES cells and introduced the mutation into the mouse germ line. Mice heterozygous for the mutant allele were phenotypically normal, whereas homozygous mice died in utero at $\sim \mathrm{E} 9.5$ as a consequence of an underdeveloped vasculature. Embryos for the null mutation or hemizygous for the dominant-negative transgene displayed strikingly similar developmental defects. Taken together, these results demonstrate that the Tek signaling pathway plays a critical role in the vascularization of the mouse embryo.

\section{Results}

Generation of transgenic mice carrying a tek $c D N A$ encoding a dominant-negative Tek RTK

To assess rapidly the role of the Tek signaling pathway in mouse development, we introduced a mutation within the tek cDNA that altered the codon for lysine853 to encode an alanine residue. This lysine residue and its surrounding amino acids are found in a region within the intracellular cytoplasmic domain that is highly conserved in all tyrosine kinases, and alteration of this residue is known to abolish catalytic function (Nocka et al. 1990; Reith et al. 1990, 1993). Furthermore, other RTKs that are competent to bind ligand, but lack intrinsic kinase activity, act in a dominant-negative fashion to inhibit signal transduction by wild-type receptor coexpressed in the same cell (Amaya et al. 1991; Ray et al. 1991; Reith et al. 1993; Millauer et al. 1994). To determine whether the lysine-to-alanine mutation at codon 853 affected the intrinsic tyrosine kinase activity of Tek, we introduced this mutated tek cDNA (tek ${ }^{\mathrm{A} 853}$ ) into COS cells and analyzed extracts from these cells for Tek activity. As shown in Figure 1, $\mathrm{Tek}^{\mathrm{A} 853}$ protein was catalytically inactive in autophosphorylation and phosphorylation of exogenously added substrate (Fig. 1B; data not shown|. Moreover, the engineered mutation did not alter the length of the protein as judged by its gel mobility (Fig. 1B).

Previous studies by our group and others have suggested that the $\beta$-actin, polyoma, and tek promoters were good candidates to drive expression of the $t e k^{\mathrm{A} 853} \mathrm{cDNA}$ 

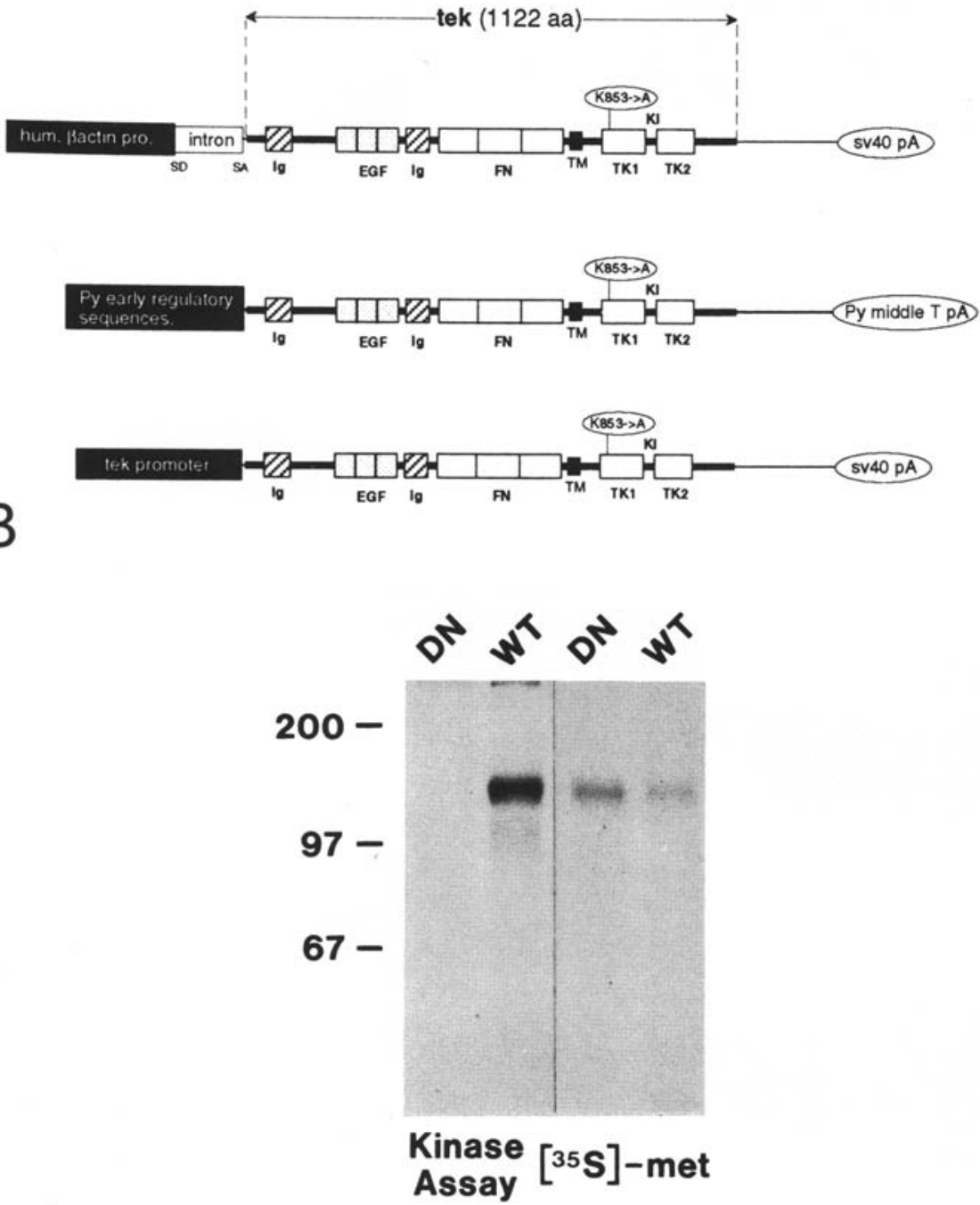

Figure 1. Tek dominant-negative transgenes. $(A)$ Schematic showing the transgenes used to drive the expression of the dominant-negative mutant $t e k^{\mathrm{A} 853} \mathrm{cDNA}$. The solid rectangle represents the promoter region for each transgene; the splice donor (SD) and acceptor (SA) of the $\beta$-actin promoter are indicated; the immunoglobulin (Ig)-, epidermal growth factor (EGF)-, and fibronectin type III-like (FN) repeats found in the extracellular region of Tek are depicted by hatched, stippled, and open boxes, respectively; the smaller solid box represents the transmembrane region (TM); the two kinase domains (TK1 and TK2) are depicted by open boxes separated by the kinase insert $(\mathrm{KI})$; ovals at the end of each transgene represent the different viral polyadenylation sequences. The oval above TK1 represents the position of the Lys $\rightarrow$ Ala-853 mutation. (B) $\mathrm{Tek}^{\mathrm{A} 853}$ is catalytically inactive. Both the $t e k^{\mathrm{A} 853}$ and wild-type tek cDNAs were expressed in COS cells using the mammalian expression vector $\mathrm{pECE}$. Transfected COS cells were labeled metabolically with $\left[{ }^{35} \mathrm{~S}\right] \mathrm{me}$ thionine and immunoprecipitated with anti-Tek antiserum. The immunoprecipitates were split and a portion used in an in vitro kinase assay (two left lanes); whereas the other was electrophoresed in a gel similar to the one used to analyze the products of the kinase assay, but after electrophoresis the gel was processed for fluorography (two right lanes). (DN) Dominant-negative mutant tek ${ }^{\mathrm{A} 853}$; (WT) wild-type tek cDNA. within the endothelial cell lineage of transgenic mice (Fig. 1A) (Bautch et al. 1987; Williams et al. 1988; Dubois et al. 1991; M. Puri, D. Dumont, and M. Breitman, in prep).

tek ${ }^{A 853}$ transgenic mice are delayed developmentally and exhibit a defect in their endothelium

On the basis of the assumption that tek may play a critical role in the endothelial cell lineage, we removed transgenic founder embryos on days 9.5 and 10.5 of gestation, 2-3 days after the onset of tek expression (Dumont et al. 1992, and in prep.). As shown in Table 1, embryos transgenic for the $\beta$-actin-tek ${ }^{\mathrm{A} 853}$ transgene showed no discernible phenotype. In contrast, two of six transgenic embryos containing the tek promoter-tek ${ }^{\mathrm{A} 853}$ transgene were delayed or arrested in their development (Table 1; data not shown). Interestingly, one of these embryos isolated on E9.5 had an enlarged pericardial cavity and contained few blood cells in the vessels of the yolk sac. This could be caused by hemorrhaging into the yolk sac cavity, as primitive red blood cells were observed there. Furthermore, 5 of 19 transgenic polyoma promoter-tek ${ }^{\mathrm{A} 853}$ embryos exhibited a developmental delay phenotype (Table 1). Of these delayed embryos, two appeared to have arrested early in development around day 8.0 as judged by the closure of their neural folds. The three other embryos were delayed in their development to varying levels but appeared morphologically normal when compared with embryos of the same size. One embryo was developmentally arrested but proved to be negative for the presence of the transgene by PCR. This embryo was an amorphous mass that was undergoing resorption, suggesting that its development was arrested before the onset of tek expression and, thus, was considered to be phenotypically distinct. 
Table 1. Delayed development among Tek ${ }^{A 853}$ dominant-negative transgenic embryos

\begin{tabular}{lcccc}
\hline \multirow{2}{*}{$\begin{array}{l}\text { Transgene } \\
\text { recovered }\end{array}$} & $\begin{array}{l}\text { Total transgenic } \\
\text { (TG) }\end{array}$ & $\begin{array}{l}\text { Total development } \\
\text { delayed (DD) }\end{array}$ & DD-TG/DD \\
\hline${\text { Polyoma } t e k^{\text {A853 }}}_{\text {tek-tek }^{\text {A853 }}}$ & 126 & 19 & $6^{\mathbf{a}}$ & $2^{\mathbf{b}} / 6$ \\
B-Actin-tek $^{\text {A853 }}$ & 64 & 6 & 0 & $2 / 2$ \\
\hline
\end{tabular}

${ }^{a}$ All embryos were obtained for analysis of E9.5, except two were discovered with the polyoma-driven transgene on E10.5 and one with the tek promoter on E10.5.

b One embryo comprised a small amorphous mass of necrotic cells that was undergoing resorption at the time of assay. As such, it was considered to be phenotypically distinct from the group of transgenic embryos showing the Tek ${ }^{\text {A853 }}$ dominant-negative phenotype.

Histological analysis of the developmentally delayed transgenic embryos was carried out on all tek ${ }^{\mathrm{A} 853}$ founders isolated on day 9.5 (Table 1), but was not performed on day 10.5 founders because of severe necrosis of the specimens. The heart of the tek promoter-tek ${ }^{\mathrm{A} 853}$ transgenic embryos was reduced in size when compared with their normal littermates (data not shown). The organization of the trabeculae within the heart appeared to be relatively normal; however, there was a reduction in the number and complexity of the branching structures (Fig. 2A,C). The endothelial cells of the endocardium of the heart were fewer in number and had a short ribbonlike structure that may reflect degeneration. The developmentally delayed embryos observed after microinjection of the polyoma promoter-tek ${ }^{\mathrm{A} 853}$ transgene manifested phenotypes that varied in their severity. Histological analysis of three of these transgenic embryos revealed no clear pathological abnormalities, although
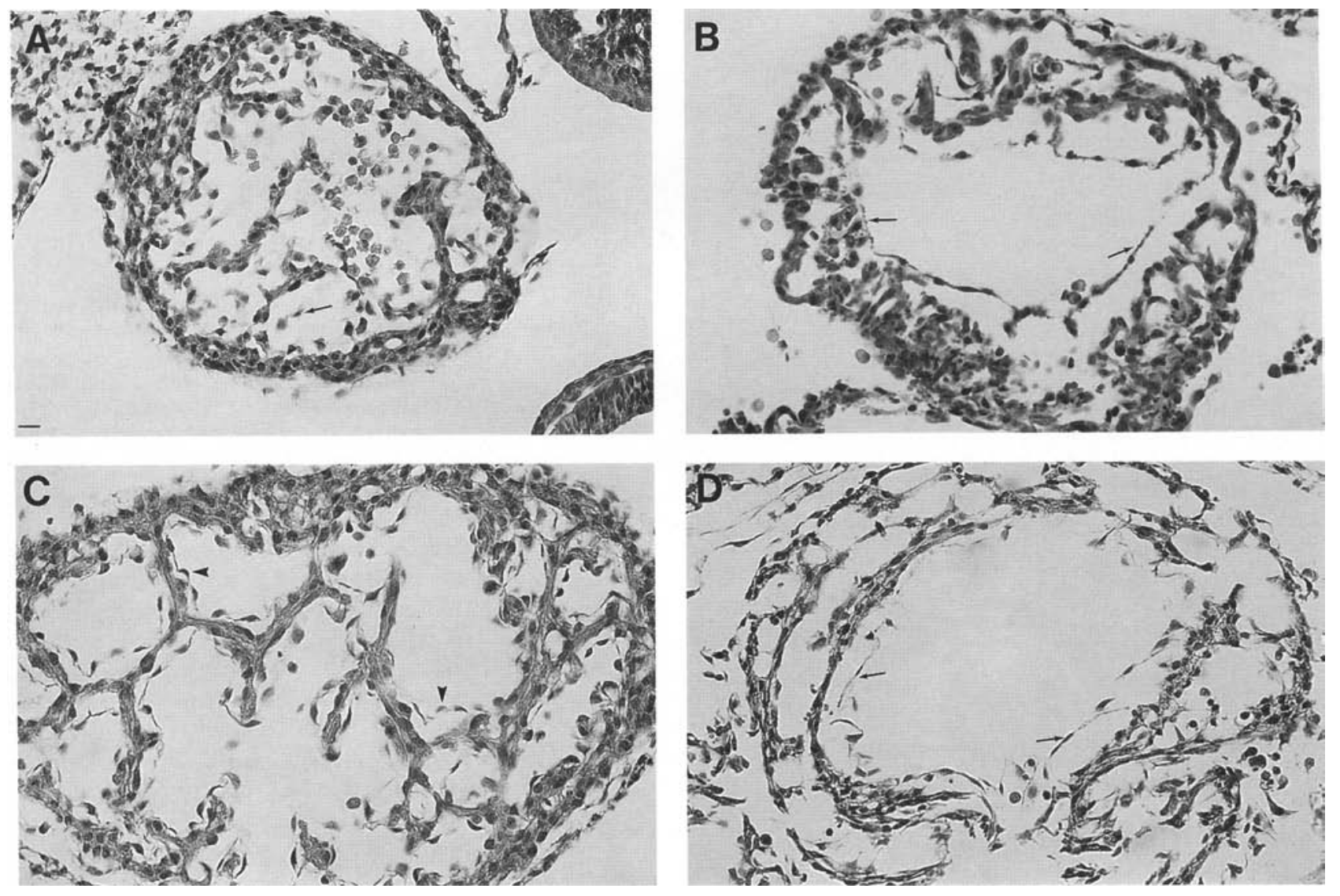

Figure 2. Histological examination of the heart regions from dominant-negative $t e k^{\mathrm{A} 853}$ transgenic and $t e k^{\Delta s p} /+$ heterozygous and homozygous embryos. E9.5 transgenic embryos, containing the $t e k^{\mathrm{A} 853}$ transgene were driven by either the tek promoter $(A)$ or the polyoma early sequences $(B)$. tek ${ }^{\Delta s p} /+$ heterozygous $(C)$ and homozygous $(D)$ embryos are shown. tek ${ }^{\Delta s p} /+$ heterozygous embryos $(C)$ showed normal (arrowheads), whereas transgenic tek promoter $(A)$ and polyoma promoter-tek ${ }^{\mathrm{A} 853}(B)$ and the $t e k^{\Delta \mathrm{sp} /}+\mathrm{homozygous}$ $(D)$ embryos showed degenerating endothelium (arrows) within their heart regions. All sections are photographed at the same magnification. Bar, $10 \mu \mathrm{m}$. 
subtle abnormalities could not be excluded. In contrast, the embryo used to produce the section in Figure 2B represented the most extreme phenotype where a defect could be distinguished clearly after dissection (data not shown). Thin sections of the heart depicted a pathology virtually indistinguishable from that observed for $t e k^{\Delta s \text { s }_{-}}$ targeted homozygous mutant embryos (Fig. 2D; see below). The development and number of trabeculae within this polyoma promoter-tek ${ }^{\mathrm{A} 853}$ and $t e k^{\Delta \mathrm{sp}_{\text {- }} \text { targeted ho- }}$ mozygous mutant hearts was severely reduced and myocardial development seemed to be affected adversely (Fig. 2B,D). The endothelial cells of the endocardium were few in number and not closely associated with the myocardium. In addition, the endothelial cells had small granules on their surfaces, which may be calcium deposits indicating cell death or cellular degeneration.

No other overt phenotype was observed for any of the tek ${ }^{\mathrm{A} 853}$ dominant-negative embryos, demonstrating that expression of this protein in other cellular compartments had no effect. Moreover, the fact that a phenotype was seen with the endothelial-specific tek promoter ar- gues that the observed phenotypes for both the tek- and polyoma promoter-driven transgenes were intrinsic to a defect in the vascular endothelium.

\section{Disruption of the tek gene in ES cells and germ-line transmission of the mutation}

To create a null allele of $t e k$, we deleted the last $52 \mathrm{bp}$ of exon 1 (Fig. 3A), encoding the first 17 amino acids of Tek, by homologous recombination in ES cells. This deletion removes both the start of translation and the signal peptide. Therefore, we refer to this mutant as $t e k^{\Delta s p}$. A positive/negative-type targeting vector (Mansour et al. 1993) was engineered by cloning $7.2 \mathrm{~kb}$ of $5^{\prime}$ genomic sequence upstream of a bacterial neomycin (neo) cassette (Tybulewicz et al. 1991) and $0.7 \mathrm{~kb}$ of $3^{\prime}$ genomic sequences downstream. In two separate experiments, linearized targeting vector was electroporated into R1 ES cells (Nagy et al. 1993). A properly targeted event was observed (Fig. 3B; data not shown) by Southern blot with both $3^{\prime}$ external and internal probes. Two independent

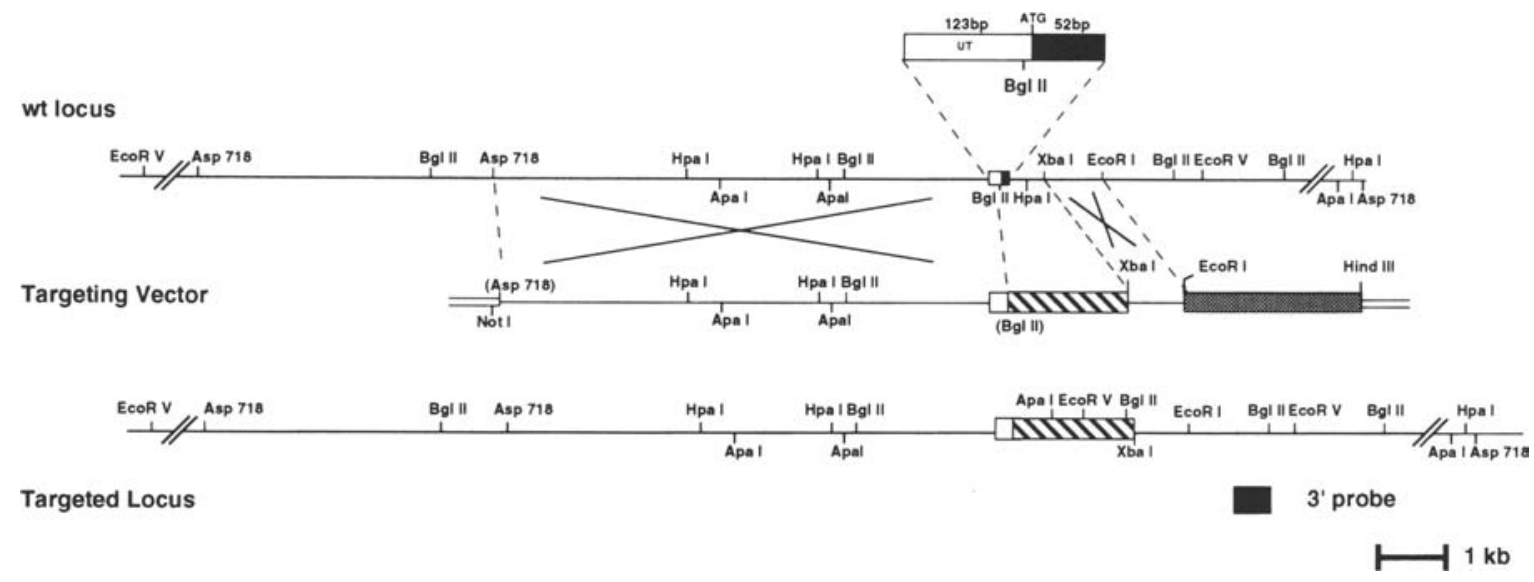

B

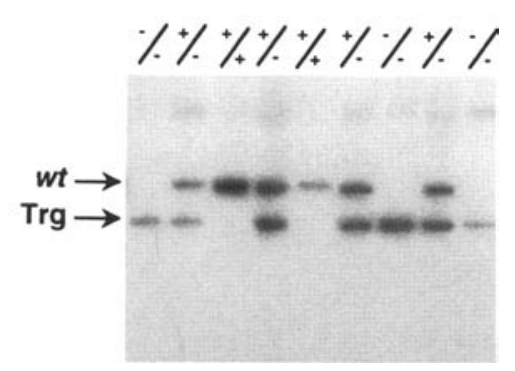

Figure 3. Disruption of the tek locus and Southern blot analysis of wild-type, tek $k^{\Delta s p}$ heterozygous and homozygous DNA. (A) Schematic showing the strategy used to disrupt the coding sequences of the first exon of the tek gene, generating the mutation $t e k^{\Delta s p}$. The solid rectangle represents the protein-coding sequences; the open rectangle represents the untranslated (UT) sequences. The phosphoglycerate kinase ( $\mathrm{PGK}$-neo expression cassette, represented by a hatched rectangle, was inserted in the same transcriptional orientation as the tek gene. The stippled rectangle represents the PGK- $t k$ (thymidine kinase) expression cassette fused to plasmid sequences represented by small, open-ended boxes. The XbaI and EcoRI restriction sites are not indicated $5^{\prime}$ of the first exon. The brackets around the $5^{\prime}$ Asp718I site signify that the site was destroyed as a consequence of cloning. The location of the $3^{\prime}$ external probe is indicated by a solid box beneath the predicted targeted locus. (B) DNA extracted from day 9.5 embryos from a $t e k^{\Delta \mathrm{sp} /}+$ hetero-

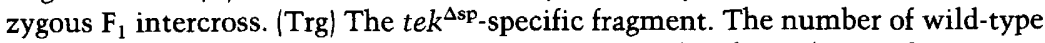
$1+1+1$, heterozygous $(+1-1$, and homozygous $(-1-)$ embryos $\{2,4$ and 3 , respectively) were at the predicted Mendelian frequency. 
ES cell lines carrying the $t e k^{\Delta s p}$ allele were injected into host $\mathrm{C} 57 \mathrm{BL} / 6 \mathrm{~J}$ blastocysts to generate chimeras that transmitted the mutation to their offspring.

\section{tek $^{\Delta s p}$ homozygous mice die during gestation}

$\mathrm{F}_{1}$ intercrosses of $t e k^{\Delta s p} /+$ mice produced no live offspring homozygous for the $t e k^{\Delta s p}$ allele (Table 2); therefore, mothers from these intercrosses were sacrificed and embryos were genotyped. At E9.5, some embryos from the heterozygous cross were visibly defective, showing some signs of necrosis, and their hearts were not beating. These embryos were all homozygous for the $t e k^{\Delta \mathrm{sp}} \mathrm{mu}$ tation (Table 2). No live homozygous mutant embryos were found beyond E9.5 (Table 2). At E12.5, none of the embryos $(0 / 35)$ were $t e k^{\Delta \mathrm{sp}}$ homozygotes; however, there were eight severely necrosed implantations, suggesting that $t e k^{\Delta s p}$ homozygous embryos implanted but then died. Genotyping of embryos isolated on E9.5 demonstrated that the proportion of embryos that were wild type, heterozygous, and homozygous for the $t e k^{\Delta s p}$ allele followed the expected Mendelian frequency, confirming that Tek is not required for implantation of the embryo (Table 2).

\section{Hemorrhaging of tek ${ }^{\Delta s p} / \mathrm{tek}^{\Delta s p}$ embryos}

Day 8.5 embryos homozygous for the $t e k^{\Delta s p}$ mutation were readily discernible by the grossly abnormal morphology of their yolk sacs, which were engorged with blood and had a cobblestone-like appearance (Figs. 4F and 5). To date, all embryos with this morphologically distinct yolk sac that have been genotyped have been homozygous $t e k^{\Delta s p}(9 / 9)$. Histological analysis of the yolk sacs from homozygous embryos harvested on E9.5 revealed that the blood vessels in the yolk sac appeared distended and were very often packed with blood (Fig. $4 \mathrm{~F}$; data not shown). Furthermore, several yolk sacs isolated from homozygous embryos contained little or no blood (Fig. 4F). Before dissection of these embryos, however, blood could be detected in the yolk sac cavity, indicating that the lack of blood in the yolk sac vasculature was caused by hemorrhaging. In addition, the yolk sac vessels contained considerably fewer endothelial cells

Table 2. Genotypes of progeny of $F_{1}$ intercrosses of $\mathrm{tek}^{\Delta s p} /+$ heterozygous mice

\begin{tabular}{lrrrrrrr}
\hline & \multicolumn{5}{c}{ Genotypes } \\
\cline { 2 - 4 } \cline { 5 - 7 } Clone & $+1+$ & $+1-$ & $-1-$ & $+1+$ & $+1-$ & $-1-$ \\
\cline { 2 - 6 } \cline { 5 - 7 } & 108 & 57 & 0 & 9 & 6 & 7 \\
19 & 11 & 4 & 0 & 3 & 1 & 1 \\
Total & 119 & 61 & 0 & 12 & 7 & 8 \\
\hline
\end{tabular}

Genotyping was carried out by Southern analysis on DNA extracted from tails or from the dissected head of embryos (see Materials and methods; Fig. 3B).
(Fig. 4F) than heterozygous littermates (Fig. 4C). Vascular hemorrhaging of homozygous embryos could also be detected histologically when the trunk region was examined. Primitive blood cells could be seen throughout the body of the embryo distributed among the mesenchymal cells (Fig. 4B,E). The dorsal aorta in heterozygous embryos was well defined with endothelial cells lining the lumen of the vessel, and there was no blood in the trunk (Fig. 4B). In contrast, in homozygous embryos the endothelium of the dorsal aorta was disorganized and appeared to have ruptured, resulting in blood cells in the body (Fig. 4E). This localized hemorrhaging of the embryonic vasculature most likely results in a decrease in the embryonic blood pressure that may explain the accumulation of blood in the yolk sac vasculature and embryonic portion of the placenta (Fig. 4D; data not shown). This region of the placenta also had very few endothelial cells in the sinuses of the placenta as compared with a heterozygous littermate (Fig. 4A,D). These results clearly demonstrate that $t e k^{\Delta \mathrm{sp}} / t^{\mathrm{a}} \mathrm{k}^{\Delta \mathrm{sp}}$ embryos have a striking deficiency in the endothelium, resulting in hemorrhaging and pooling of blood in body cavities.

The hearts of $t e k^{\Delta s p}$ homozygous embryos were severely underdeveloped (see Fig. 2D). The myocardium of E9.5 mutant embryos did not possess a detailed organization of trabeculae, and the overall growth of the myocardium seems to be reduced. Furthermore, fewer endothelial cells were seen in the endocardium (see Fig. 2D).

\section{Analysis of flk-1, tek, and tie expression in tek ${ }^{\Delta s p}$ embryos}

That there were few remaining endothelial cells in homozygous embryos was confirmed by RNA in situ hybridization of sections prepared from both $t e k^{\Delta s p}$ homozygous and heterozygous embryos with a flk-1 antisense riboprobe. Both heterozygous and homozygous embryos (data not shown) contained flk-1-positive cells organized in a distinctive vascular network. However, the flk-1-positive cells in homozygous mutant embryos were present in discontinuous chains, suggesting that the vessels contained a sparsely populated endothelium (data not shown). Moreover, the levels of $f 1 k-1$ expression were lower in the homozygous mutants. Adjacent sections probed for the expression of tek and tie demonstrated that tie transcripts were present, albeit at lower levels than in heterozygous embryos (data not shown), whereas no tek signals could be detected in homozygous $t e k^{\Delta \mathrm{sp}}$ embryos (data not shown). These results demonstrate that the $t e k^{\Delta \mathrm{sp}}$ mutant allele does not produce a normal transcript, confirming that it is a null allele. Interestingly, these results also demonstrate that tie expression in endothelial cells is not dependent on prior expression of tek.

tek $^{\Delta s p} /$ tek $^{\Delta s p}$ embryos have a reduced number of endothelial cells

To follow the fate of $t e k$-expressing endothelial cells in 

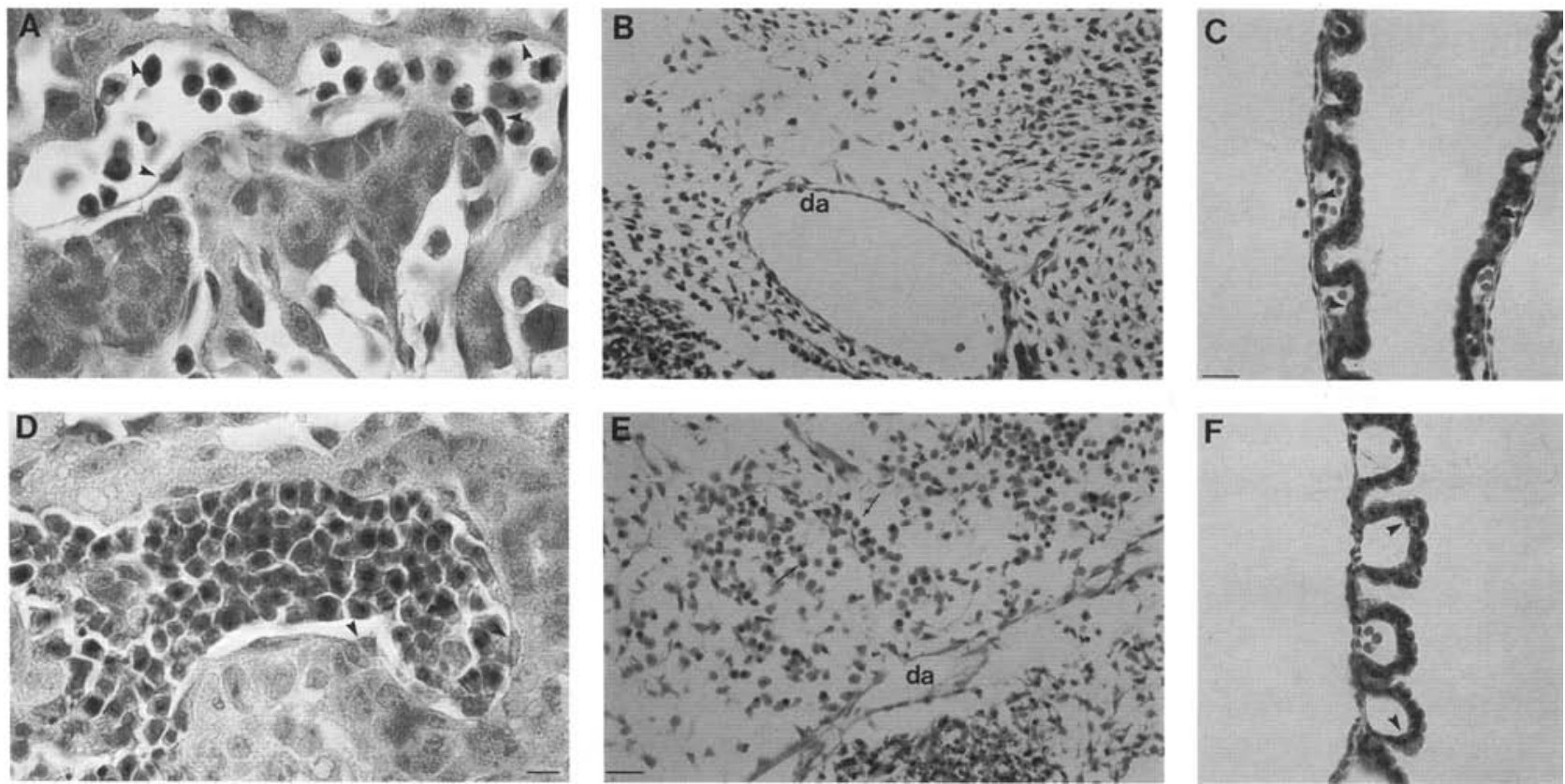

Figure 4. Histological analysis of homozygous tek mutant embryos and normal littermates. Sections through the embryonic portion of the placenta from tek $k^{\Delta s p}$ heterozygous $\{A\}$ and homozygous $\{D \mid$ embryos showing the accumulation of fetal blood cells in the placental sinuses in homozygous embryos. These sections also illustrate the decreased number of endothelial cells in the sinus of mutants as compared with normal littermates (arrowheads). Bar, $10 \mu \mathrm{m}$. Thin sections taken through the dorsal aortic region of heterozygous $(B)$ and homozygous $(E)$ embryos showing the collapsed aorta (da) and extravasated blood (arrows). Bar, $30 \mu \mathrm{m}$. Stained thin sections through the yolk sac of tek ${ }^{\Delta s p}$ heterozygous $(C)$ and homozygous $(F)$ embryos showing the distended yolk sac vessels and the decreased number of endothelial cells lining the yolk sac vessels (arrowheads). Bars, $30 \mu \mathrm{m}$.

mutant embryos, we crossed a tek promoter-lac $Z$ transgene gene onto the $t e k^{\Delta s p}$ mutant background. Adult mice bearing the tek promoter-lacZ, tek ${ }^{\Delta \mathrm{sp}} /+$ genotype were then used to generate homozygous embryos carrying the $t e k^{\Delta s p}$ mutation and the transgene. The tek promoter-lacZ transgenic line used in these studies expresses the lac $Z$ reporter gene in a manner that virtually recapitulates the endogenous tek expression profile (M.C. Puri, D. Dumont, and M. Breitman, in prep.).

On the basis of $\beta$-galactosidase ( $\beta$-gal) activity, $t e k^{\Delta s p}$ homozygous embryos isolated on E8.5 and E9.0 contained a normally patterned vasculature in both extraembryonic and embryonic tissues (Fig. 5). Moreover, the size of normal and homozygous embryos at these gestational ages were the same (data not shown), suggesting that the growth of the embryo up to E9.0 is not dependent on Tek. However, it is clear that the level of $\beta$-gal staining in these homozygous embryos was reduced (Fig. $5 \mathrm{C}, \mathrm{D})$. Histological examination of E9.0 homozygous embryos confirmed that proper patterning of the vasculature was initiated (Fig. 6). Furthermore, the endocardium and other vascular structures of mutant embryos formed correctly but contained only low levels of lac $Z$ expression, in keeping with the low levels of $f l k-1$ and tie expression detected in these cells (Fig. 6B,D; data not shown).

Histological analysis of the yolk sacs of $t e k^{\Delta s p}$ homozygous mutants revealed that the number of $1 a c Z$ expressing endothelial cells lining the blood islands was reduced in E8.5 tek ${ }^{\Delta s p}$ homozygous embryos (Fig. 7C) compared with their normal littermates (Fig. 7A). This decrease in cell number and staining intensity was even more accentuated in sections taken from E9.0 homozygous embryos (Fig. 7B,D). The blood islands also contained cells with an endothelial cell-like morphology that did not stain blue, whereas this was never observed in normal transgenic mice.

Table 3 summarizes the number of blue endothelial cells found in the yolk sacs of transgenic embryos. The number of endoderm cells found in each blood island did not vary significantly for any of the embryos and, thus, was used to normalize the values. Day $8.5 t e k^{\Delta \mathrm{sp}}$ homozygous embryos possessed $\sim 30 \%$ fewer endothelial cells within the blood islands as compared with their normal littermates. On E9.0, one-half day later in development, $75 \%$ fewer endothelial cells were detected in the yolk sac of $t e k^{\Delta s p}$ homozygous mutant embryos. These results clearly demonstrate that the number of endothelial cells present within homozygous embryos at the times analyzed is significantly lower than that of their normal littermates and that as development progresses the number of endothelial cells decreases. Moreover, the very low levels of lacZ expression detected in many cells suggests that these cells are probably compromised metabolically and are dying.

\section{Discussion}

In this study we have demonstrated that embryos ho- 
Figure 5. The yolk sac vasculature of $t e k^{\Delta s p}$ homozygous embryos contains fewer endothelial cells. tek promoter-lac $Z$ transgene expression in day 8.5 normal $(A)$ and $t e k^{\Delta s p}$ homozygous $(C)$ embryos shows a reduced number of blue-staining endothelial cells in the homozygous mutants. The decreased number of blue cells larrowheads) is even more dramatic in the yolk sac of day 9.0 tek $^{\Delta s p}$ homozygous $(D)$ embryos, as compared with normal embryos (B). Bar, $50 \mu \mathrm{m}$.
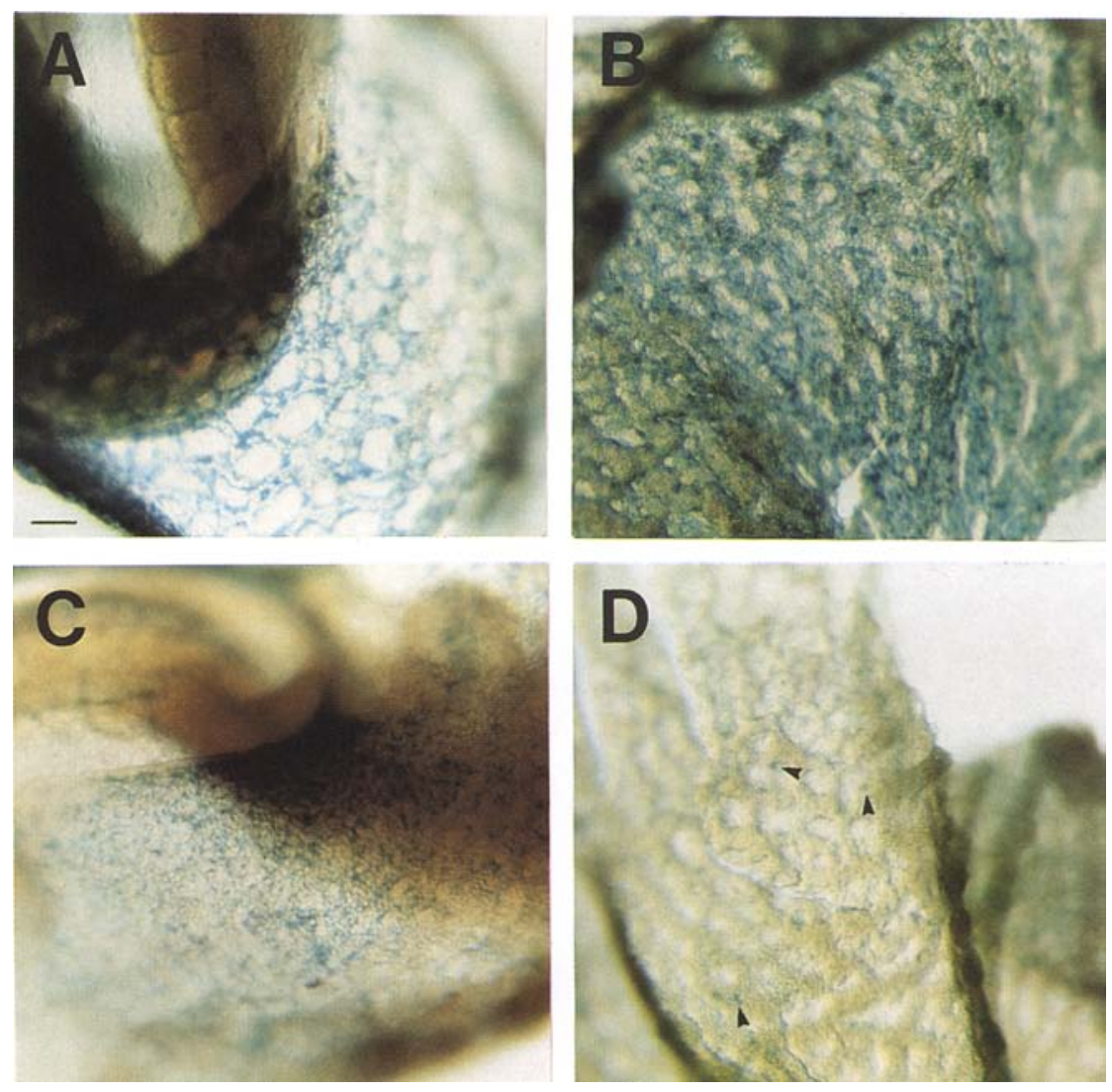

mozygous for a null mutation in the tek RTK gene or expressing dominant-negative forms of the Tek receptor die in utero, with visible abnormalities in their endothelium, compromised heart development, and hemorrhaging. These data provide definitive genetic evidence that the Tek RTK, whose expression is almost exclusively restricted to cells of the endothelial cell lineage (Dumont et al. 1992 and in prep.), is critical for proper vasculature development.

\section{Tek is required for maintenance and/or proliferation of endothelial cells, not for the production of angioblasts and differentiation into endothelial cells}

The vasculature of the embryo has its origins in both the extraembryonic and embryonic mesoderm. Mesenchymal cells differentiate into angioblasts that then give rise to endothelial cells (Noden 1989, 1991; Coffin et al. 1991). te ${ }^{\Delta s p}$ homozygous embryos have multiple signs of vascular hemorrhaging, either because endothelial cells fail to develop in these embryos or develop and then die because of the absence of Tek. We were able to address this question by following the fate of tek-expressing cells in embryos homozygous for the tek mutation and carrying a $l a c Z$ reporter transgene driven by the endothelial cell-specific tek promoter. These experiments showed that the relative number of endothelial cells decreased as development progressed, arguing that Tek is not absolutely required for the elaboration of the endothelial cell lineage but is necessary for the subsequent expansion of this lineage as the embryo grows in size. The finding that homozygous $t e k^{\Delta \mathrm{sp}}$ embryos survive to day 8.5 suggests that the number of endothelial cells produced by this Tek-independent pathway can support growth of the embryo only up to this size, after which the integrity of the vasculature is compromised, leading to hemorrhaging and embryonic death.

The loss of endothelial cells in $t e k^{\Delta s p}$ homozygous embryos after E8.5 may also be an active process if Tek is responsible for transducing a survival stimulus. Thus, Tek-deficient endothelial cells may embark on a programmed cell death or apoptotic pathway. The lower levels of lacZ-expressing cells in the cross described here, as well as the lower number of $f 1 k-1$ - and tie-positive cells in homozygous embryos, suggest that perhaps this may be the case and that these cells die selectively in the absence of an intact Tek-signaling pathway.

\section{Interaction of the endothelium and the myocardium during cardiogenesis}

Apart from vascular hemorrhaging, the most striking phenotype detected in $t e k^{\Delta s p}$ homozygous mutant embryos was an underdeveloped heart. The primitive myocardial and endocardial rudiments of the murine heart develop in situ from the pericardial wall and subadjacent 

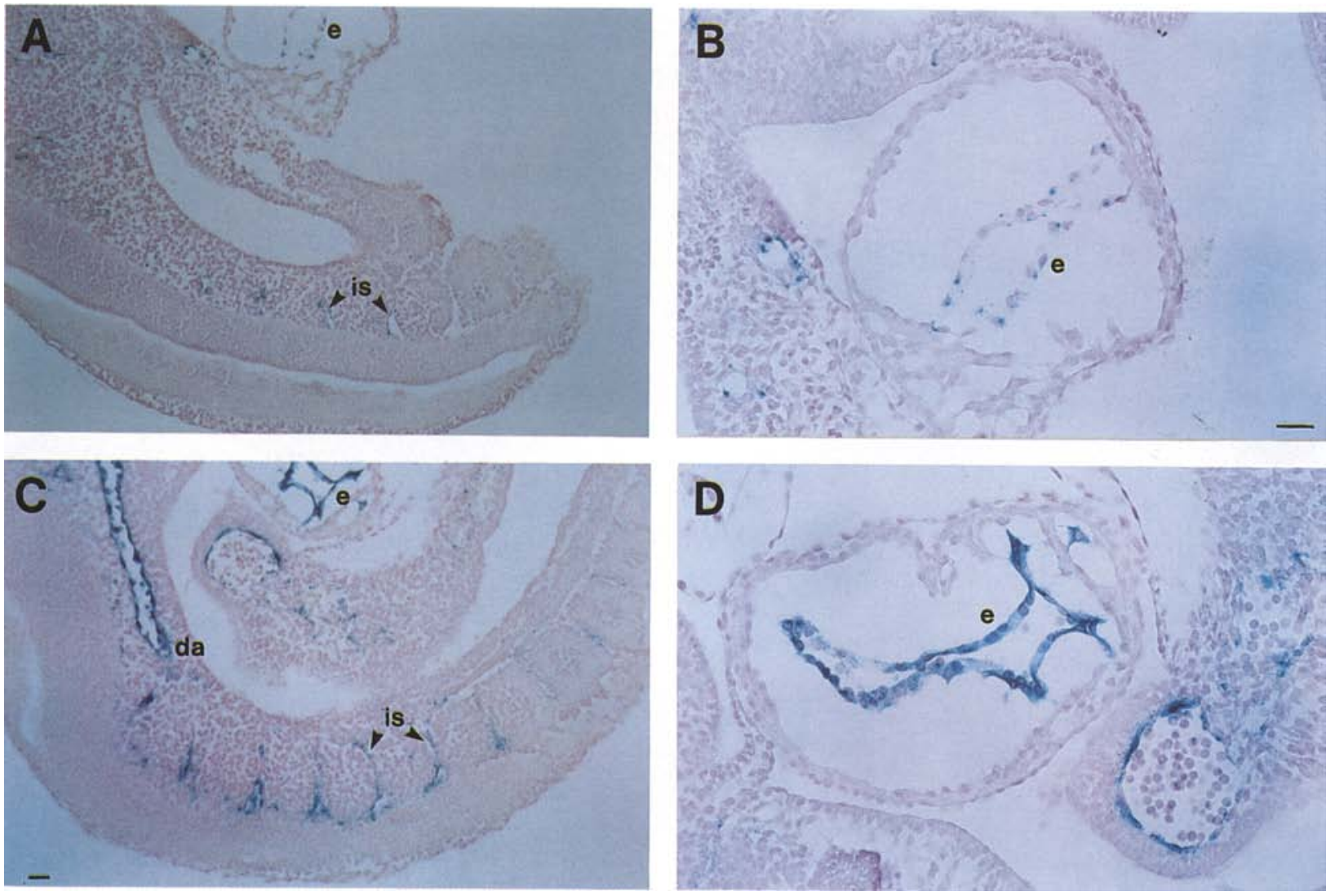

Figure 6. The embryonic vasculature of tek ${ }^{\Delta s p}$ homozygous embryos contain fewer endothelial cells. The trunk $(A, C)$ and heart $(B, D)$ regions of a $\mathrm{E} 9.0$ tek $^{\Delta \mathrm{sp}}$ homozygous $(A, B)$ and wild-type $(C, D)$ embryos. A lower levels of lacZ expression is seen in the intersegmental vessels (is) and endocardium (e) of mutants. (da) Dorsal aorta. Bars, $50 \mu \mathrm{m}$.

mesenchyme, respectively (Kaufman and Navaratnam 1981). These two structures are thought to interact during differentiation of the heart, and one of the products of this interaction is the cardiac jelly found between the endocardium and the myocardium (Kaufman and Navaratnam 1981). tek is expressed in the angioblasts (Dumont et al. 1992) that arise from the mesenchyme and give rise to the endothelium of the embryo and to the endocardium (Kaufman and Navaratnam 1981). Very early during development (E8.5), these structures were present in both the tek ${ }^{\Delta s p}$ homozygous and wild-type embryos, suggesting that, although tek is expressed in these cells, the early differentiation processes leading to these structures are Tek independent. Moreover, later in development (E9.5), the myocardium was severely retarded in growth, and the endocardium, which also had an abnormal appearance, was not associated closely with the myocardium supporting a role for endocardial/myocardial interactions later in heart development. However, we cannot exclude the possibility that the abnormal myocardial development is secondary to the endothelial cell defect.

These data also are consistent with the possibility that Tek is responsible for directly mediating the endocardial/myocardial interactions. These interactions could result either because Tek is a ligand for another receptor present in the myocardium or because Tek can act directly as an adhesion molecule to mediate this interaction. If these possibilities are correct, one would predict that the catalytic function of Tek would not be required for these interactions; however, the very similar phenotype of the Tek dominant-negative (Tek-DN) mutants argues that catalytic activity is required for Tek function.

\section{Tyrosine kinase activity is required for Tek function}

In these studies we have shown that expression of a TekDN molecule in transgenic mice results in developmental delay and/or arrest. Histological analysis revealed that several of the embryos had abnormalities in their endothelium, including fewer endothelial cells, which were apparently degenerating.

This phenotype was very similar to embryos with a targeted null mutation, $t e k^{\Delta s p}$, which had fewer endothelial cells, compromised heart development, and hemorrhaging. The extracellular domain of Tek contains several cell adhesion motifs that are known to play roles in cellular motility, cell recognition, and/or ligand binding (Bevilacqua 1993). The virtually identical phenotype of 
Figure 7. Endothelial cells in the yolk sac of $t e k^{\Delta s p}$ homozygous embryos express low levels of the tek-lacZ transgene. Thin sections taken from the yolk sacs presented in Fig. 5 illustrate tek promoter-lacZ expression (arrowheads) in the endothelial cells of E8.5 $(A, C)$ and E9.0 $(B, D) t^{t e k^{\Delta s}}$ homozygous $(C, D)$ and wild-type $(A, B)$ embryos. These photomicrographs show both a reduction in the number of blue-staining endothelial cells and a decrease in the levels of $\beta$-galactosidase activity in the mutants. In addition, increased blood cell number can be seen in the blood vessels of $t e k^{\Delta s p}$ homozygous embryos. Bars, $25 \mu \mathrm{m}(A, C)$; $12.5 \mu \mathrm{m}(B, D)$.
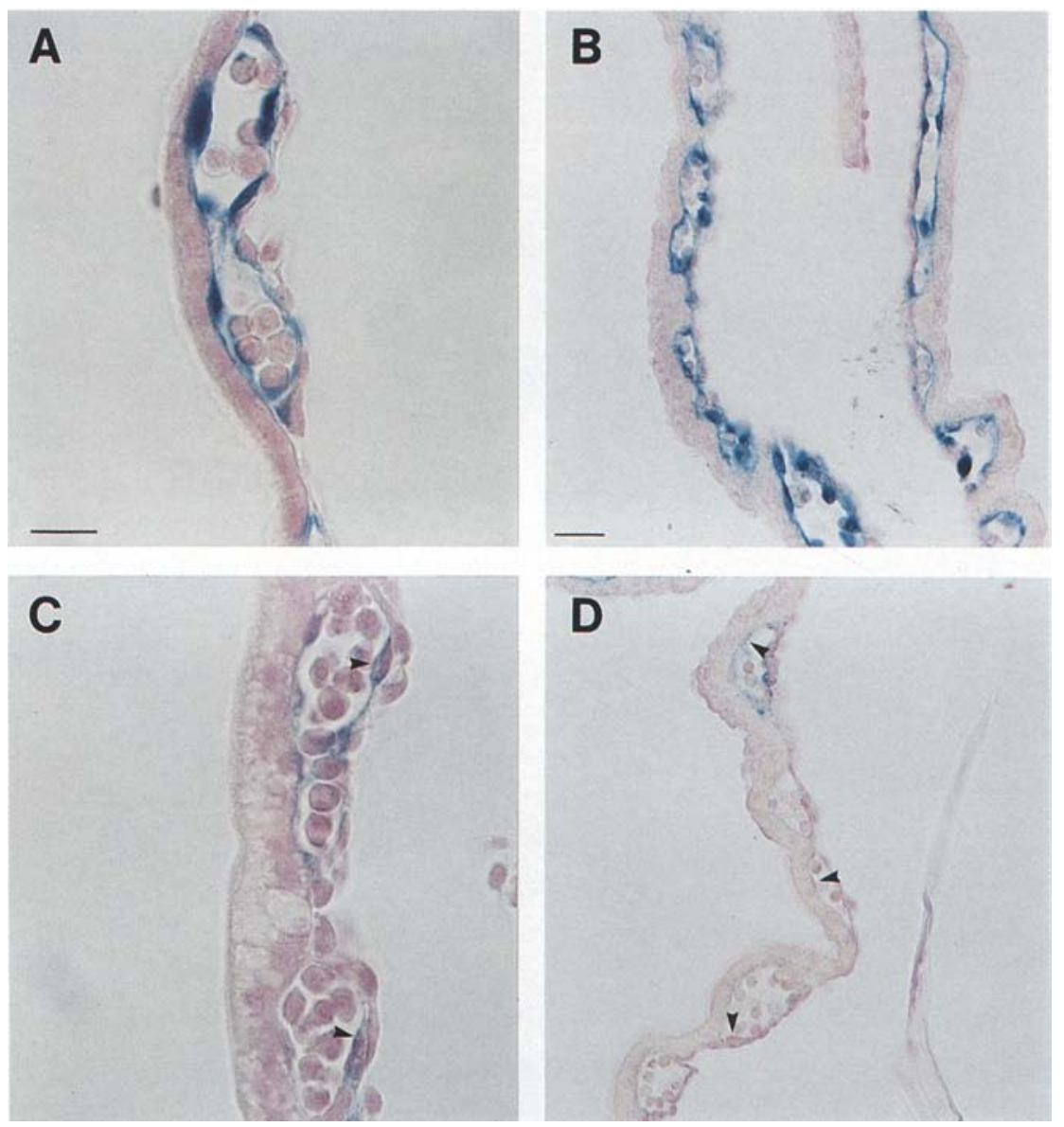

the most extreme Tek-DN mutant and the targeted null $t e k^{\Delta \mathrm{sp}}$ homozygous embryos demonstrates that expression of a catalytically inactive receptor is not sufficient for normal Tek function; rather, these data argue that the intrinsic tyrosine kinase of the Tek receptor is obligatory for development.

\section{Do Tek and Tie heterodimerize?}

The dimerization and heterodimerization of RTKs upon ligand binding has been well established (Reith and Bern- stein 1991; Schlessinger and Ullrich 1992). Whether Tek and Tie bind similar ligands as heterodimers and/or homodimers is not known as their ligands have not been identified. Furthermore, the extracellular domains of these RTKs share a common overall structure; however, their primary amino acid sequence homology is low, suggesting that Tek and Tie bind distinct ligands. Moreover, the similar phenotype of dominant-negative and mutant homozygous $t e k^{\Delta \mathrm{sp}}$ embryos suggests that Tek signals as a homodimer, although the possibility that Tek and Tie signal as obligate heterodimers cannot be excluded.

Table 3. The ratio of lacZ-positive endothelial cells to endoderm cells in the yolk sacs of embryos of $F_{1}$ intercrosses of tek-lacZ/tek-lacZ; tek $^{\Delta s p} /+$ mice

\begin{tabular}{lcccc}
\hline $\begin{array}{l}\text { Gestational age } \\
\text { (days) }\end{array}$ & $\begin{array}{l}\text { tek } \\
\text { Genotype }\end{array}$ & $\begin{array}{l}\text { Total no. of } \\
\text { endoderm cells } \\
\text { per blood island }\end{array}$ & $\begin{array}{l}\text { Total no. of } \\
\text { lacZ -expressing cells } \\
\text { per blood island }\end{array}$ & $\begin{array}{l}\text { No. of lacZ } \\
\text { cells per 100 } \\
\text { endoderm cells }\end{array}$ \\
\hline 8.5 & $+/-$ & $7.8 \pm 0.9(24)$ & $4.5 \pm 0.7$ & $54 \pm 12$ \\
8.5 & $-1-$ & $6.1 \pm 1.1(45)$ & $1.0 \pm 0.8$ & $35 \pm 7$ \\
9.0 & $+/-$ & $11.8 \pm 0.3(27)$ & $4.7 \pm 0.6$ & $39 \pm 6$ \\
9.0 & $-/-$ & $11.8 \pm 3(21)$ & $1.1 \pm 0.9$ & $8 \pm 4$ \\
\hline
\end{tabular}

${ }^{a}$ Numbers reflect the mean \pm S.D., and the number in brackets represents the number of blood islands counted per section. 


\section{Are the Tek and Tie signaling pathways redundant?}

$t e k^{\Delta s p}$ homozygous embryos express tie at the normal time, demonstrating that tie expression is not dependent on tek. The finding that tie is expressed in homozygous $t e k^{\Delta s p}$ mutants suggests that the closely related Tie receptor is unable to compensate for the lack of Tek. However, tie is normally expressed half a day later than tek during development (D. Dumont, G.-H. Fong, M. Puri, G. Gradwohl, K. Alitalo, and M. Breitman, in prep.). Thus, if even these two RTKs have completely overlapping signaling pathways, their different temporal patterns of expression may preclude simple functional redundancy in a dying embryo. Alternatively, Tie and Tek may not bind the same ligand; thus, Tie would not be able to transduce a signal intracellularly in response to the Tek ligand. It is also possible that Tek and Tie are activated by the same ligand but have distinct downstream signaling pathways as a result of differences in their kinase insert and carboxy tail (Dumont et al. 1993). The Tek-DN phenotype is very similar to the homozygous $t e k^{\Delta s p}$ mutant phenotype, supporting the idea that the Tek-DN protein is interfering specifically with only the Tek signaling pathway.

In summary, we have presented genetic evidence that Tek, one of five known RTKs whose expression is primarily restricted to endothelial cells, is absolutely required in the mouse for normal development of the vasculature. Our data argue that Tek function is not required for the initial appearance of early endothelial cells but, rather, for their subsequent survival and/or proliferation. It will be interesting to determine whether any of the other four RTKs play a critical role in the early developmental decisions to give rise to this important lineage.

\section{Materials and methods}

\section{Generation of the tek ${ }^{A 853}$ dominant-negative transgenes and transgenic embryos}

The codon for lysine- 853 was altered by oligonucleotide-directed mutagenesis (Amersham) to the codon encoding an alanine residue. The entire cDNA fragment used in this mutagenesis was sequenced completely before subcloning back into the full-length tek cDNA. The mutated cDNA $\left(t e k^{\mathrm{A} 853}\right)$ was cloned into the mammalian expression vector pECE (Ellis et al. 1987) and transfected into COS cells as described (Dumont et al. 1993). Metabolic labeling and tyrosine kinase assays were done with an anti-Tek antibody as described (Lhotak and Pawson 1993). Two of the three transgenes were made by cloning the $t^{2} k^{\mathrm{A} 853}$ cDNA upstream of the SV40 polyadenylation [poly(A)] sequences (BamHI-XbaI) and then cloning this cassette downstream of the large $\beta$-actin promoter (gift of V. Giguiere, Hospital for Sick Children, Toronto, Canada) or the 7.2-kb tek promoter (M. Puri, D. Dumont, and M. Breitman, in prep.). The polyoma promoter-driven transgene was constructed by cloning the tek ${ }^{\mathrm{A} 853}$ cDNA without the SV40 poly(A) sequences into $\operatorname{pdPX}_{13} \mathrm{Bla}_{3} \mathrm{MT}_{5}$ (Bautch et al. 1987) in which the sequences coding for polyoma middle $\mathrm{T}$-antigen had been removed by $B s t \mathrm{XI}$ digestion. These transgenes all contained 3 '-untranslated sequences from the tek cDNA; thus, whether transcription terminated at the tek poly(A) sequences or the viral poly(A) se- quences is not known. DNAs from these constructs were prepared and injected into fertilized oocytes, as described previously (Logan et al. 1993). Embryos were analyzed on days 9.5 and 10.5 postinjection and were genotyped by PCR analysis of yolk sac DNA prepared as described (Frohman et al. 1990) using a primer that annealed within the tek 3 '-untranslated sequence (CCTCACCTGCAGAAGCCAGTTTGT) and primers within either the SV40 (GTGGTTTGTCCAACTCATCAATG) or polyoma (CTACCATAATCCAGTCTACTGC) poly(A) sequences.

Transgene expression levels could not be ascertained by RNA in situ analysis using probes directed against the viral poly(A) sequences, suggesting that either they were not used and that the tek poly(A) sequences within the tek cDNA were used or that the levels were too low to be detected.

\section{tek targeting vector}

The tek genomic clone used in these studies was obtained from a $129 \mathrm{~Sv}$ mouse strain library. The targeting vector consisted of a long arm 7.2-kb Asp 718I-Bg/II genomic fragment located 5' of the tek-coding sequences and a short arm of $0.7 \mathrm{~kb}$ extending from $X b a$ I to the EcoRI sites immediately $3^{\prime}$ of the first exon (Fig. 3). These two fragments were cloned on either side of the phosphoglycerate kinase (PGK)-neo expression cassette of the pPNT vector (Tybulewicz et al. 1991) such that the direction of neo transcription was in the same orientation as tek. Upon homologous recombination, this vector will delete $\sim 0.7 \mathrm{~kb}$ of genomic sequences that includes 14 bp of untranslated sequence, the first 52 nucleotides of the protein-coding sequence, and $\sim 650$ bp of the first intron.

\section{Generation and genotyping of tek ${ }^{\Delta s p}$ mice}

Rl (Nagy et al. 1993) ES cells were propagated, electroporated, plated, and selected as described (Joyner et al. 1989). Selection in gancyclovir resulted in an enrichment of 7-and 32-fold in the two experiments. Four targeted clones were identified ( 1 in 232 and 3 in 55, respectively). Taken together, the frequency of homologous recombination was $\sim 1$ in $960 \mathrm{G} 418^{\mathrm{R}}$ clones. The identification of targeted events was accomplished by Southern blot analysis on ES cell DNA extracted directly in 24-well culture dishes as described (Wurst and Joyner 1993) and digested with BglII. A 0.3-kb AccI-BglII genomic DNA fragment located immediately $3^{\prime}$ to the short arm was used as probe. This probe recognizes a wild-type fragment of $2.5 \mathrm{~kb}$ and a targeted fragment of $1.9 \mathrm{~kb}$ (Fig. 3B). Confirmation of a correctly targeted event was accomplished by Southern analysis of DNA extracted from heterozygous mice and digested with multiple enzymes. The probes used were the $3^{\prime}$ external and two other internal probes consisting of the neo-coding sequences and a genomic DNA fragment of $0.4 \mathrm{~kb}$ (SpeI-BgIII) found 5 ' to the proteincoding sequences (data not shown). No nonrepetitive probes could be found $5^{\prime}$ of the Asp718I site. Injection of ES cells carrying the $t e k^{\Delta s p}$ mutation into $C 57 \mathrm{BL} / 6 \mathrm{~J}$ blastocysts was performed as described previously (Joyner et al. 1989). Genotyping of offspring was carried out on DNA extracted from either tails or the dissected heads of embryos. The tek-lac $Z$ transgenic mouse line is described (M.C. Puri, D.J. Dumont, and M. Breitman, in prep). Genotyping of lacZ transgenic animals was determined by Southern analysis using $1 a c Z$-coding sequences as probe.

Mice heterozygous for the $t e k^{\Delta s p}$ mutation had no apparent abnormalities and were fertile. Intercrosses of mice derived from both independent ES cell clones were carried out between either outbred (129SvJ $\times$ C57BL/6J) $F_{1}$ or inbred 129SvJ $F_{1}$ mice to allow analysis on two genetic backgrounds. No differences in 
phenotype were observed on either of the two genetic backgrounds or the two targeted ES cell lines.

\section{Histology and lacZ staining}

Midday of the vaginal plug was considered as day 0.5 postcoitum in the staging of embryos. To date, all embryos with a cobblestone-like appearing yolk sac were homozygous for the $t e k^{\Delta \mathrm{sp}}$ mutation. Therefore, to conserve material, embryos used in the lacZ expression studies were judged to be homozygous for the $t e k^{\Delta s p}$ mutation based on this criteria. Staining for the presence of $\beta$-gal in whole-mount embryos was performed as described (Logan et al. 1993). Stained embryos were postfixed in formalin at room temperature overnight and processed for wax embedding, sectioned at $6 \mu \mathrm{m}$, and counterstained with nuclear-fast red. Quantification of the number of lacZ-expressing (blue) endothelial cells was accomplished by selecting a single section of an embryo and counting the number of endoderm and blue endothelial cells per blood island. Subsequent histological analysis of these mutants revealed other abnormalities characteristic of homozygous mutants that confirmed the phenotyping. For histological and RNA in situ analysis, the heads of embryos were removed for DNA extraction and genotyping before fixing the embryos overnight in freshly prepared $4 \%$ paraformaldehyde at $4^{\circ} \mathrm{C}$. After fixation embryos were processed for wax embedding, sectioned at 4-6 $\mu \mathrm{m}$, and either used for RNA in situ analysis or stained with hematoxylin-eosin.

\section{Acknowledgments}

We gratefully acknowledge $\mathrm{K}$. Harpal for preparation and sectioning all embryonic tissues; Dr. W. Wurst for his invaluable instruction to D.J.D. on ES cell culture; Dr. K. Alitalo for the tie probe; Dr. J. Hassel for $\operatorname{pdPX}_{13} \mathrm{Bla}_{3} \mathrm{MT}_{5}$; Drs. A. Bernstein and A. Joyner for critical reading of the manuscript; the gene targeting group for helpful discussions; and Z. Krzyzek for excellent secretarial assistance. This work was supported by Bristol MyersSquibb and the National Cancer Institute of Canada. M.C.P. is an Ontario graduate scholar. The late M.L.B. was an MRC scientist.

The publication costs of this article were defrayed in part by payment of page charges. This article must therefore be hereby marked "advertisement" in accordance with 18 USC section 1734 solely to indicate this fact.

\section{References}

Amaya, E., T.J. Musci, and M.W. Kirschner. 1991. Expression of a dominant negative mutant of the FGF receptor disrupts mesoderm formation in Xenopus embryos. Cell 66: 257270.

Bautch, V.L., S. Toda, J.A. Hassell, and D. Hanahan. 1987. Endothelial cell tumors develop in transgenic mice carrying polyoma virus middle $\mathrm{T}$ oncogene. Cell 51: 529-538.

Bevilacqua, M.P. 1993. Endothelial-leukocyte adhesion molecules. Annu. Rev. Immunol. 11: 767-804.

Coffin, J.D., J. Harrison, S. Schwartz, and R. Heimark. 1991. Angioblast differentiation and morphogenesis of the vascular endothelium in the mouse embryo. Dev. Biol. 148: 5162.

Dubois, N.A., L.C. Kolpack, R. Wang, R.G. Azizkhan, and V.L. Bautch. 1991. Isolation and characterization of an established endothelial cell line from transgenic mouse hemangiomas. Exp. Cell Res. 196: 302-313.

Dumont, D.J., T.P. Yamaguchi, R.A. Conlon, J. Rossant, and
M.L. Breitman. 1992. tek, a novel tyrosine kinase gene located on mouse chromosome 4, is expressed in endothelial cells and their presumptive precursors. Oncogene 7: 14711480.

Dumont, D.J., G.J. Gradwohl, G.-H. Fong, R. Auerbach, and M.L. Breitman. 1993. The endothelial-specific receptor tyrosine kinase, tek, is a member of a new subfamily of receptors. Oncogene 8: 1293-1301.

Eichmann, A., C. Marcelle, C. Bréant, and N.M. Le Douarin. 1993. Two molecules related to the VEGF receptor are expressed in early endothelial cells during avian embryonic development. Mech. Dev. 42: 33-48.

Ellis, L., D.O. Morgna, S.M. Jong, L.H. Wang, R.A. Roth, and W.J. Rutter. 1987. Heterologous transmembrane signalling by a human insulin receptor-v-ros hybrid in Chinese hamster ovary cells. Proc. Natl. Acad. Sci. 84: 5101-5105.

Frohman, M.A., M. Boyle, and G.R. Martin. 1990. Isolation of the mouse Hox-2.9 gene; analysis of embryonic expression suggests that positional information along the anterior-posterior axis is specified by mesoderm. Development 110: 589607.

Hunter, T. and R.A. Lindberg. 1994. Receptor protein-tyrosine kinases. Frontiers Mol. Biol. (in press).

Iwama, A., I. Hamaguchi, M. Hashiyama, Y. Murayama, K. Yasunaga, and T. Suda. 1993. Molecular cloning and characterization of mouse tie and tek receptor tyrosine kinase genes and their expression in hematopoietic stem cells. Biochem. Bioph. Res. Comm. 195: 301-309.

Joyner, A.L., W.C. Skarnes, and J. Rossant. 1989. Production of a mutation in mouse En-2 gene by homologous recombination in embryonic stem cells. Nature 338: 153-156.

Kaipainen, A., J. Korhonen, K. Pajusola, O. Aprelikova, M.G. Perisco, B.L. Torman, and K. Alitalo. 1994. The related FLT4, FLT1 and KDR receptor tyrosine kinases show distinct expression patterns in human fetal endothelial cells. J. Exp. Med. 178: 2077-2088.

Kaufman, M.H. and V. Navaratnam. 1981. Early differentiation of the heart in mouse embryos. I. Anat. 133: 235-246.

Lhotak, V. and T. Pawson. 1993. Biological and biochemical activities of a chimeric epidermal growth factor-Elk receptor tyrosine kinase. Mol. Cell. Biol. 13: 7071-7079.

Logan, C., W.K. Khoo, D. Cado, and A.L. Joyner. 1993. Two enhancer regions in the mouse En-2 locus direct expression to the mid-hindbrain region and mandibular myoblasts. $D e$ velopment 117: 905-916.

Maisonpierre, P.C., M. Goldfarb, G.D. Yancopoulos, and G. Gao. 1993. Distinct rat genes with related profiles of expression define a TIE receptor tyrosine kinase family. Oncogene 8: $1631-1637$.

Mansour, S.L., J.M. Goddard, and M.R. Cappechi. 1993. Mice homozygous for a targeted disruption of the proto-oncogene int-2 have developmental defects in the tail and inner ear. Development 117: 13-28.

Matsushime, H., M. Yoshida, M. Sasaki, and M. Shibuya. 1987. A possible new member of tyrosine kinase family, human $F R T$ sequence, is highly conserved in vertebrates and located on human chromosome 13. Jpn. J. Cancer Res. 78: 655-661.

Millauer, B., S. Wizigmann-Voos, H. Schnürch, R. Martinez, N.-P.H. Moller, W. Risau, and A. Ullrich. 1993. High affinity VEGF binding and developmental expression suggest Flk-1 as a major regulator of vasculogenesis and angiogenesis. Cell 72: 835-846.

Millauer, B., L.K. Shawver, K.H. Plate, W. Risau, and A. Ullrich. 1994. Glioblastoma growth inhibited in vivo by a dominantnegative Flk-1 mutant. Nature 367: 576-579.

Nagy, A., J. Rossant, R. Nagy, W. Abramow-Newerly, and J.C. 
Roder. 1993. Viable cell culture-derived mice from early passage embryonic stem cells. Proc. Natl. Acad. Sci. 90: 8424 8428.

Nocka, K., J.C. Tan, E. Chiu, T.Y. Chu, P. Ray, P. Traktman, and P. Besmer. 1990. Molecular basis of dominant negative and loss of function mutations at the murine c-kit/while spotting locus $\mathrm{W}^{37}, \mathrm{~W}^{\mathrm{v}}, \mathrm{W}^{41}$ and W. EMBO I. 9: 1805-1813.

Noden, D.M. 1989. Embryonic origins and assembly of blood vessels. Am. Rev. Respir. Dis. 140: 1097-1103.

1991. Origins and assembly of avian embryonic blood vessels. Ann. N.Y. Acad. Sci. 1: 236-249.

Pajusola, K., O. Aprelikova, J. Korhonen, A. Kaipainen, L. Pertovaara, R. Alitalo, and K. Alitalo. 1992. FLT4 receptor tyrosine kinase contains seven immunoglobulin-like loops and is expressed in multiple human tissues and cell lines. Cancer Res. 52: 5738-5743.

Partanen, J., E. Armstrong, T.P. Makela, J. Korhonen, M. Sandberg, R. Renkonen, S. Knuutila, K. Huebner, and K. Alitalo. 1992. A novel endothelial cell surface receptor tyrosine kinase with extracellular epidermal growth factor homology domains. Mol. Cell. Biol. 12: 1698-1707.

Pawson, T. 1993. Signal transduction a conserved pathway from the membrane to the nucleus. Dev. Genet. 14: 333-338.

Pawson, T. and A. Bernstein. 1991. Receptor tyrosine kinases: Genetic evidence for their role in Drosophila and mouse development. Trends Genet. 6: 350-356.

Peters, K.G., C. de Vries, and L.T. Williams. 1993. Vascular endothelial growth factor receptor expression during embryogenesis and tissue repair suggests a role in endothelial differentiation and blood vessel growth. Proc. Natl. Acad. Sci. 90: 8915-8919.

Ray, P., K.M. Higgins, J.C. Tan, T.Y. Chu, N.S. Yee, H. Nguyen, E. Lacy, and P. Besmer. 1991. Ectopic expression of a c-kit ${ }^{\text {W42 }}$ minigene in transgenic mice: Recapitulation of $W$ phenotypes and evidence for $\mathrm{c}-\mathrm{kit}$ function in melanoblast progenitors. Genes \& Dev. 5: 2265-2273.

Reith, A.D. and A. Bernstein. 1991. Molecular basis of mouse developmental mutants. Genes \& Dev. 5: 1115-1123.

Reith, A.D., R. Rottapel, F. Giddens, C. Brady, L. Forresterm, and A. Bernstein. 1990. W mutant mice with mild or severe developmental defects contain distinct point mutations in the kinase domain of the c-kit receptor. Genes \& Dev. 74: 390-400.

Reith, A.D., C. Ellis, N. Maroc, T. Pawson, A. Bernstein, and P. Dubreuil. 1993. "W" mutant forms of the Fms receptor tyrosine kinase act in a dominant manner to suppress CSF-1 dependent cellular transformation. Oncogene 8: 45-53.

Sato, T.N., Y. Qin, C.A. Kozak, and K.L. Audus. 1993. tie-1 and tie-2 define another class of putative receptor tyrosine kinase genes expressed in early embryonic vascular system. Proc. Natl. Acad. Sci. 90: 9355-9358.

Schlessinger, J. and A. Ullrich. 1992. Growth factor signalling by receptor tyrosine kinases. Cell 9: 383-391.

Shibuya, M., S. Yamaguchi, A. Yamane, T. Ikedo, A. Tojo, H. Matsushime, and M. Sato. 1990. Nucleotide sequence and expression of a novel human receptor-type tyrosine kinase gene $(f l t)$ closely related to the fms family. Oncogene 5: 519524.

Terman, B.I., M.E. Carrion, E. Kovacs, B.A. Rasmussen, R.L. Eddy, and T.B. Shows. 1991. Identification of a new endothelial cell growth factor receptor tyrosine kinase. Oncogene 9: 1677-1683.

Tybulewicz, V.L.J., C.E. Crawford, P.K. Jackson, R.T. Bronson, and R.C. Mulligan. 1991. Neonatal lethality and lymphopenia in mice with a homozygous disruption of the c-abl protooncogene. Cell 65: 1153-1163.
Wilks, A.F. 1989. Two putative protein-tyrosine kinases identified by application of the polymerase chain reaction. Proc. Natl. Acad. Sci. 86: 1603-1607.

Williams, R.L., S.A. Courtneidge, and E.F. Wagner. 1988. Embryonic lethalities and endothelial tumors in chimeric mice expressing polyoma virus middle T oncogene. Cell 52: 121131.

Wurst, W. and A.L. Joyner. 1993. Production of targeted embryonic stem cell clones. In Gene targeting. (ed. A.L. Joyner), pp. 33-61. Oxford University Press, New York.

Yamaguchi, T.P., D.J. Dumont, R.A. Conlon, M.L. Breitman, and J. Rossant. 1993. flk-1, an flt-related receptor tyrosine kinase is an early marker for endothelial cell precursors. $D e$ velopment 118: 489-498.

Ziegler, S.F., T.A. Bird, J.A. Schneringer, K.A. Schooley, and P.R. Baum. 1993. Molecular cloning and characterization of a novel receptor protein tyrosine kinase from human placenta. Oncogene 8: 663-670. 


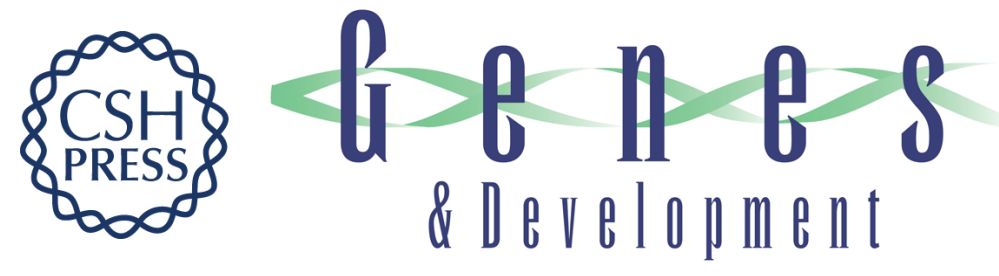

\section{Dominant-negative and targeted null mutations in the endothelial receptor tyrosine kinase, tek, reveal a critical role in vasculogenesis of the embryo.}

D J Dumont, G Gradwohl, G H Fong, et al.

Genes Dev. 1994, 8:

Access the most recent version at doi:10.1101/gad.8.16.1897

References This article cites 43 articles, 14 of which can be accessed free at:

http://genesdev.cshlp.org/content/8/16/1897.full.html\#ref-list-1

License

Email Alerting Service

Receive free email alerts when new articles cite this article - sign up in the box at the top right corner of the article or click here.

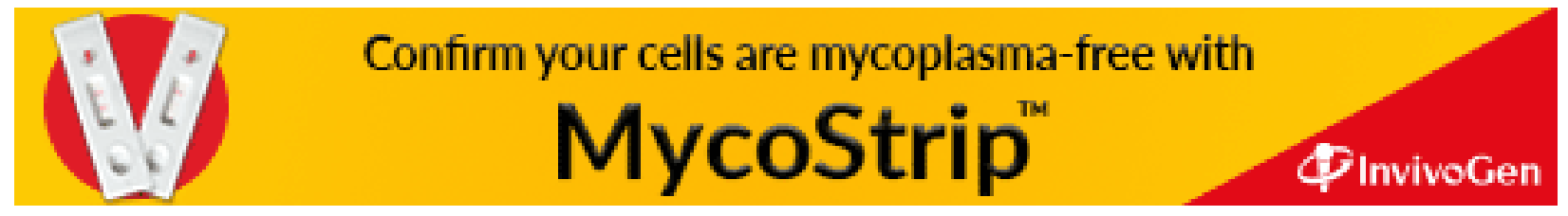

